\title{
Evaluation of $\mathrm{C} 2$ pedicle screw placement via the freehand technique by neurosurgical trainees
}

\author{
Martin H. Pham, MD, Joshua Bakhsheshian, MD, Patrick C. Reid, MD, Ian A. Buchanan, MD, \\ Vance L. Fredrickson, MD, and John C. Liu, MD \\ Department of Neurosurgery, Keck School of Medicine, University of Southern California, Los Angeles, California
}

\begin{abstract}
OBJECTIVE Freehand placement of $\mathrm{C} 2$ instrumentation is technically challenging and has a learning curve due the unique anatomy of the region. This study evaluated the accuracy of $\mathrm{C} 2$ pedicle screws placed via the freehand technique by neurosurgical resident trainees.

METHODS The authors retrospectively reviewed all patients treated at the LAC+USC Medical Center undergoing C2 pedicle screw placement in which the freehand technique was used over a 1-year period, from June 2016 to June 2017; all procedures were performed by neurosurgical residents. Measurements of C2 were obtained from preoperative CT scans, and breach rates were determined from coronal reconstructions on postoperative scans. Severity of breaches reflected the percentage of screw diameter beyond the cortical edge $(\mathrm{I}=<25 \%$; II $=26 \%-50 \%$; III $=51 \%-75 \%$; IV = 76\%-100\%).
\end{abstract}

RESULTS Neurosurgical residents placed $40 \mathrm{C} 2$ pedicle screws in 24 consecutively treated patients. All screws were placed by or under the guidance of Pham, who is a postgraduate year 7 (PGY-7) neurosurgical resident with attending staff privileges, with a PGY-2 to PGY-4 resident assistant. The authors found an average axial pedicle diameter of 5.8 $\mathrm{mm}$, axial angle of $43.1^{\circ}$, sagittal angle of $23.0^{\circ}$, spinal canal diameter of $25.1 \mathrm{~mm}$, and axial transverse foramen diameter of $5.9 \mathrm{~mm}$. There were 17 screws placed by PGY-2 residents, 7 screws placed by PGY-4 residents, and 16 screws placed by the PGY-7 resident. The average screw length was $26.0 \mathrm{~mm}$, with a screw diameter of $3.5 \mathrm{~mm}$ or $4.0 \mathrm{~mm}$. There were 7 total breaches (17.5\%), of which 4 were superior $(10.0 \%)$ and 3 were lateral $(7.5 \%)$. There were no medial breaches. The breaches were classified as grade I in 3 cases (42.9\%), II in 3 cases (42.9\%), III in 1 case (14.3\%), and IV in no cases. There were 3 breaches that occurred via placement by a PGY-2 resident, 3 breaches by a PGY-4 resident, and 1 breach by the PGY-7 resident. There were no clinical sequelae due to these breaches.

CONCLUSIONS Freehand placement of C2 pedicle screws can be done safely by neurosurgical residents in early training. When breaches occurred, they tended to be superior in location and related to screw length choice, and no breaches were found to be clinically significant. Controlled exposure to this unique anatomy is especially pertinent in the era of work-hour restrictions.

https://thejns.org/doi/abs/10.3171/2018.1.SPINE17875

KEYWORDS C2; cervical; freehand; pedicle screws; resident training

$\mathrm{I}$ NSTRUMENTATION and fixation of the C2 spinal segment are technically challenging and complex due to its unique spinal and extraspinal anatomy. Multiple fixation techniques have been developed over the years, inclusive of transarticular screw fixation of the atlantoaxial joint, posterior plate and screw fusion techniques, and pars and translaminar screw methods.,.$^{2,3,7}$ It was Harms and
Melcher who subsequently popularized the cannulation of the $\mathrm{C} 2$ pedicle with a minipolyaxial screw that they connected rostrally to $\mathrm{C} 1$ lateral mass screws in what became known as the Harms technique. ${ }^{4}$ The safety profile of this trajectory is described in the literature with regard to the anatomical freehand placement method. ${ }^{2,5,8}$ The objective of this study was to evaluate the complication rates of free- 
hand $\mathrm{C} 2$ pedicle screw placement as taught and placed by neurosurgical trainees at a neurosurgical residency training program.

Rigid instrumentation of the $\mathrm{C} 2$ vertebra is an important technique for the treatment of various conditions associated with cervical instability in the upper cervical spine. Pedicle screw fixation has emerged as a particularly effective approach for immobilization of the axis. Given its unique anatomy, however, placement of $\mathrm{C} 2$ pedicle screws can be technically demanding owing to the risk of injury to the vertebral arteries and nearby neural structures. ${ }^{1}$

Intraoperative fluoroscopy has been recommended to assist in determining the ideal trajectory during placement of $\mathrm{C} 2$ pedicle screws. Use of this imaging adjunct may not necessarily prevent injury to the vertebral artery, however, because of the inability to fully determine the location of the vertebral artery as it courses from $\mathrm{C} 3$ to $\mathrm{C} 1{ }^{6}{ }^{6}$ Therefore, the anatomical freehand technique has been advocated, whereby the $\mathrm{C} 2$ pars interarticularis is extensively dissected for greater exposure of the superior, medial, and lateral borders. Pedicle screws are then placed freehand using the external anatomy as landmarks to guide an optimal surgical trajectory based on the patient's preoperative imaging.

In this study, we investigated the breach rates associated with anatomical freehand placement of $\mathrm{C} 2$ pedicle screws in a series of consecutively treated patients in whom the procedures were performed by neurosurgical resident trainees at a single hospital.

\section{Methods \\ Data Collection}

We retrospectively reviewed the medical records of all patients at the LAC+USC Medical Center undergoing C2 pedicle screw placement using the anatomical freehand technique (e.g., without image guidance) over a 1-year period from June 2016 to June 2017. All patients who underwent pedicle screw placement under image guidance via fluoroscopy, CT, or neuronavigation guidance were excluded. Screws that were placed via the translaminar, transarticular, or pars interarticularis techniques were excluded. Patient age, sex, diagnosis, length of fusion, and complications were obtained.

All patients received preoperative assessments with CT and CT angiography. Morphometric measurements of C2 were obtained from preoperative CT scans of bilateral pedicles. Coronal, axial, and sagittal CT reconstructions were reviewed to determine the minimum axial pedicle diameter, minimum coronal pedicle diameter, axial transverse foramen diameter, axial pedicle angle, sagittal pedicle angle, and maximum axial canal diameter. High-riding vertebral arteries were also measured on sagittal CT reconstructions and defined as an internal height of $<2 \mathrm{~mm}$ and an isthmus height of $<5 \mathrm{~mm}$.

Postoperative CT scans were obtained the day following surgery for evaluation of $\mathrm{C} 2$ pedicle screw placement. Breach rates were determined from coronal reconstructions on postoperative CT scans. The severity of breaches reflected percentage of screw diameter beyond the cortical edge $(\mathrm{I}=<25 \%$; II $=26 \%-50 \%$; III $=51 \%-75 \%$; and $\mathrm{IV}=$

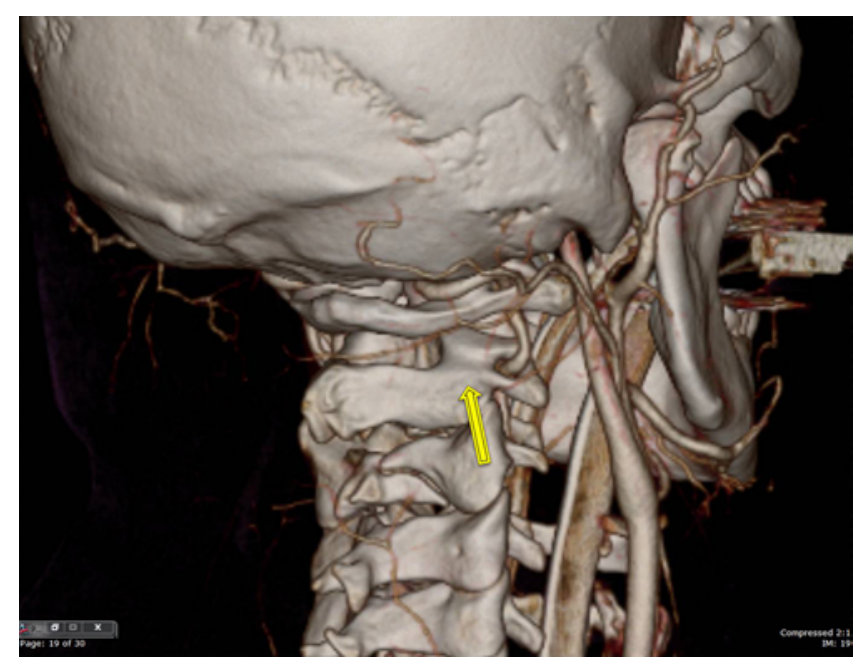

FIG. 1. A 3D CT reconstruction demonstrating both the superior and lateral starting point as well as the trajectory as guided medially by the spinal canal and superiorly just underneath the superior cortical wall. The tip of the yellow arrow denotes the starting point, and its directionality represents the trajectory taken for the freehand screw placement. Figure is available in color online only.

$76 \%-100 \%){ }^{6}$ Location of the pedicle screw violation was either medial (toward the central canal), lateral (toward the transverse foramen), or superior (toward the C1-2 joint). Measurements of preoperative anatomical parameters and postoperative $\mathrm{C} 2$ screws were conducted with blinding to postoperative clinical results.

\section{C2 Pedicle Screw Placement}

The suitability, exposure, starting point, and drill trajectory for how the $\mathrm{C} 2$ pedicle screws were placed via the freehand technique were similar to what has been described by Sciubba et al. ${ }^{6}$

Preoperative sagittal CT reconstructions were assessed to rule out the presence of a high-riding vertebral artery or if the entirety of the $\mathrm{C} 2$ pedicle could not be seen on a single sagittal image slice. In patients with these higherrisk features, the CT scans were further reviewed to assess if a pedicle screw could still be placed by tailoring a more lateralized starting point and medialized trajectory.

The screw entry point is located at the craniolateral quadrant at the lateral aspect of the $\mathrm{C} 2$ lateral mass, just caudal to the transition zone between the lateral mass and the pars interarticularis (Fig. 1). The starting point is at least $1.75 \mathrm{~mm}$ caudal to the superior surface's transition zone to allow clearance of a 3.5- to $4.0-\mathrm{mm}$ screw beneath it. This craniolateral starting point minimizes the potential for traversing the transverse foramen containing the vertebral artery if the trajectory of the screw is sufficiently medialized.

The craniocaudal trajectory of the $\mathrm{C} 2$ pedicle screw is determined under direct intraoperative visualization by the slope of the $\mathrm{C} 2$ pars, with the trajectory aiming to stay parallel to this slope just under the bony margin of the pars itself. The lateromedial trajectory is determined by identifying the cortical margin of the medial pars, which by definition is the lateral edge of the spinal canal at the 

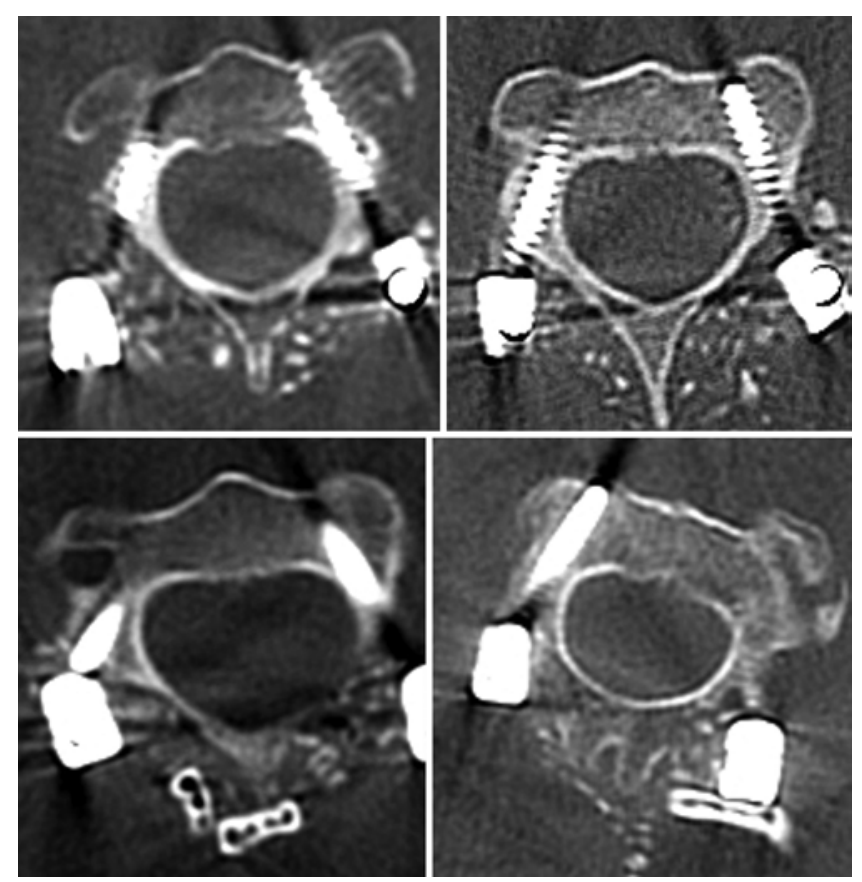

FIG. 2. Axial CT views of 4 cases demonstrating freehand $\mathrm{C} 2$ pedicle screw placement by neurosurgical resident trainees.

C2 level, lateral to the dura mater itself. The trajectory is then aimed to be tangential to the lateral edge of the canal, which would connect an imaginary line from the screw entry point traveling just past the lateral spinal canal into the vertebral body via the $\mathrm{C} 2$ pedicle.

Once the starting point and trajectory have been determined, a pilot hole is made with a small burr at the starting point. A drill guide is placed in the desired trajectory and a $3.0-\mathrm{mm}$ conical tap is advanced to $8 \mathrm{~mm}$, and then the screw hole is palpated with a ball-ended probe for cortical violations. The tap is subsequently advanced in 4- $\mathrm{mm}$ increments and reassessed until a depth of $20 \mathrm{~mm}$. Since the depth at this distance would be past any nonaberrant vertebral artery anatomy, the tap is subsequently advanced by hand until the anterior cortical margin is reached, which is suggested by the increased insertional torque of the tap. The screw hole is assessed a final time with the ball-ended probe, and the screw length is determined by length of the probe depth. The $\mathrm{C} 2$ pedicle screw is then placed. The determination of the diameter of the screw is decided based on preoperative evaluation of the CT scans and is either 3.5 or $4.0 \mathrm{~mm}$.

All C2 pedicle screws were placed by or under the guidance of one surgeon (M.H.P.), who is a postgraduate year 7 (PGY-7) resident neurosurgeon with attending staff privileges at the LAC+USC Medical Center, with a firstassistant resident neurosurgeon at the PGY-2 to PGY-4 training level. There was a total of three different PGY-2 and two different PGY-4 neurosurgery resident trainees. Surgeon M.H.P. was the attending of record for all cases, and there were no faculty attending surgeons present.

The junior neurosurgical residents performed all the steps for this maneuver, from tissue dissection to freehand placement of the actual $\mathrm{C} 2$ pedicle screw. This occurred
TABLE 1. Characteristics of patients undergoing freehand placement of $\mathrm{C} 2$ pedicle screws

\begin{tabular}{lc}
\hline \multicolumn{1}{c}{ Characteristic } & Value \\
\hline No. of patients & 24 \\
\hline No. of C2 screws & 40 \\
\hline Mean age (range), yrs & $56.1(23-91)$ \\
\hline Sex, no. (\%) & $18(75)$ \\
\hline Male & $6(25)$ \\
\hline Female & \\
\hline Etiology (\%) & $8(33)$ \\
\hline Degenerative & $14(58)$ \\
\hline Trauma & $2(8)$ \\
\hline Tumor & $7(17.5)$ \\
\hline Breaches, no. (\% total screws) & $4(57)$ \\
\hline Superior & $3(43)$ \\
\hline Lateral & $0(0)$ \\
\hline Medial & $5(71)$ \\
\hline Left & $2(29)$ \\
\hline Right & $3(42.9)$ \\
\hline Breach grade, no. (\%) & $3(42.9)$ \\
\hline I & $1(14.3)$ \\
\hline II & $0(0)$ \\
\hline III &
\end{tabular}

under the direct guidance of the PGY-7 (M.H.P.), who was present during the execution of the technique from start to finish. Prior to the cases, all junior neurosurgical residents were given a lecture on the technique by M.H.P. and given the opportunity to review a model of the $\mathrm{C} 2$ anatomy. Surgeon M.H.P. had completed an enfolded fellowship in spine surgery his prior training year, where he gained experience placing $\mathrm{C} 2$ pedicle screws freehand as taught to him by faculty attending staff that prior year.

\section{Results}

There were $40 \mathrm{C} 2$ pedicle screws inserted by neurosurgical residents in 24 consecutively treated patients (Fig. 2). The diagnosis was trauma in 14 patients, degenerative disease in 8 patients, and tumor in 2 patients (Table 1). In 8 patients, aberrant anatomy precluded the placement of bilateral pedicle screws, and so only a single screw was placed. In these cases, either a contralateral $\mathrm{C} 2$ pars screw was placed instead or no contralateral $\mathrm{C} 2$ screw was placed at all. Criteria for aberrant anatomy included very small or dysplastic C2 pedicles with an axial measurement on CT scans of $<2.5 \mathrm{~mm}$. Additionally, significantly high-riding vertebral arteries were ruled out for pedicle screw placement based on surgical judgment. Five patients did present with $6 \mathrm{C} 2$ pedicles that just met the definition of having high-riding vertebral arteries (mean internal height of 1.9 $\mathrm{mm}$, range $1.8-1.9 \mathrm{~mm}$; mean isthmus height of $4.0 \mathrm{~mm}$, range $2.2-4.8 \mathrm{~mm}$ ), and $\mathrm{C} 2$ pedicle screws were successfully placed in those pedicles via the freehand technique. There were no cases of unsuccessful screw placement or 
TABLE 2. Morphometric measurements of $\mathrm{C} 2$ pedicles

\begin{tabular}{lcc}
\hline \multicolumn{1}{c}{ Measurement } & Mean Value & Range \\
\hline Axial pedicle diameter, $\mathrm{mm}$ & 5.8 & $3.4-7.4$ \\
\hline Coronal pedicle diameter, $\mathrm{mm}^{\prime}$ & 7.7 & $6.0-11.7$ \\
\hline Axial angle, $^{\circ}$ & 43.1 & $34.0-49.0$ \\
\hline Sagittal angle, $^{\circ}$ & 23.0 & $18.0-31.0$ \\
\hline Axial spinal canal diameter, $\mathrm{mm}^{\circ}$ & 25.1 & $21.0-29.0$ \\
\hline Axial transverse foramen diameter, $\mathrm{mm}$ & 5.9 & $4.6-7.1$ \\
\hline
\end{tabular}

screw placement that was aborted due to intraoperative complications of exposure or drilling. We found an average axial pedicle diameter of $5.8 \mathrm{~mm}$ (range 3.4-7.4 mm), coronal pedicle diameter of $7.7 \mathrm{~mm}$ (range $6.0-11.7 \mathrm{~mm}$ ), axial angle of $43.1^{\circ}$ (range $34.0^{\circ}-49.0^{\circ}$ ), sagittal angle of $23.0^{\circ}$ (range $18.0^{\circ}-31.0^{\circ}$ ), spinal canal diameter of 25.1 $\mathrm{mm}$ (range $21.0-29.0 \mathrm{~mm}$ ), and axial transverse foramen diameter of $5.9 \mathrm{~mm}$ (range 4.6-7.1 mm) (Table 2).

There were 17 screws placed by PGY-2 residents, 7 screws placed by PGY-4 residents, and 16 screws placed by the PGY-7 resident (Table 3 ). The average pedicle screw length was $26.0 \mathrm{~mm}$ (range $20-32 \mathrm{~mm}$ ), with a screw diameter of $3.5 \mathrm{~mm}$ or $4.0 \mathrm{~mm}$. There were 7 total breaches $(17.5 \%)$, of which 4 were superior $(10.0 \%)$ and 3 were lateral (7.5\%) (Fig. 3). There were no medial breaches. The breaches were classified as grade I in 3 cases $(42.9 \%)$, II in 3 cases $(42.9 \%)$, III in 1 case $(14.3 \%)$, and IV in no cases. The breaches occurred on the left side in 5 cases and on the right side in 2 cases. There were 3 breaches that occurred via placement by a PGY-2, 3 breaches by a PGY-4, and 1 breach by the PGY-7 resident. There were no clinical sequelae due to these breaches.

\section{Discussion}

Posterior C1-2 screw instrumentation for immediate rigid atlantoaxial fixation was first described by Goel and Laheri in 1994. 2,3 This technique was subsequently popularized by Harms and Melcher in 2001 after which $\mathrm{C} 2$ pedicle cannulation became a commonly performed technique. ${ }^{4}$

While $\mathrm{C} 2$ pedicle screw placement can provide immediate fixation of the axis, great care must be taken not to injure the vertebral artery in the transverse foramen just lateral to the pedicle cortical wall. The freehand placement technique has since been demonstrated to be a safe method for placement of $\mathrm{C} 2$ pedicle screws without fluoroscopic guidance, provided that there is a careful evaluation of preoperative imaging to correlate with a clear intraoperative exposure of the anatomy (Table 4). Yeom et al. placed $46 \mathrm{C} 2$ screws (39 pedicle and 7 laminar) via the anatomical freehand method and reported on 8 pedicle screws $(21 \%)$ that breached the vertebral artery foramen but without any arterial injury. ${ }^{9}$ Sciubba et al. studied 100 $\mathrm{C} 2$ pedicle screws in 55 consecutive patients and found 15 breaches (15\%), while Alosh et al. found a breach rate of $25.3 \%$ in their study of $170 \mathrm{C} 2$ pedicle screws placed in 93 patients. ${ }^{1,6}$ Bydon et al. found an overall breach rate of $17.3 \%$ in 341 pedicle screws placed in 181 patients. $^{2}$

The purpose of this study was to determine the compli-
TABLE 3. Details of C2 pedicle screw placement by training level and breach

\begin{tabular}{cc}
\hline Variable & No. of Screws \\
\hline Pedicle screws placed & \\
\hline PGY-2 & 17 \\
\hline PGY-4 & 7 \\
\hline PGY-7 & 16 \\
\hline Breach by training level & 3 \\
\hline PGY-2 & 3 \\
\hline PGY-4 & 1 \\
\hline PGY-7 &
\end{tabular}

cation rate following placement of $\mathrm{C} 2$ pedicle screws via the anatomical freehand method by neurosurgical resident trainees. In our study, we tailored a superior and lateral starting point with a trajectory guided by the medial and superior aspect of the $\mathrm{C} 2$ pedicle based on individual landmarks to allow for anatomical variation among patients (Fig. 1). Oftentimes, we found that a more superior and lateral starting point allowed for a better medial trajectory that yielded a safer corridor for either small $\mathrm{C} 2$ pedicles or patients with high-riding vertebral arteries. This is consistent with what was described by Sciubba et al., where they found that a very high and lateral entry point minimized the potential for vertebral artery injury. ${ }^{6}$

Because of the unique anatomy associated with this segment, we wanted to assess the safety of controlled exposure of this surgical technique in early residency training. We found a total of 7 breaches (17.5\%), of which 4 were superior and 3 were lateral. Of the 4 screws breaching superiorly into the $\mathrm{C} 1-2$ joint, 3 occurred in patients with constructs ending at $\mathrm{C} 2$. Over an average early follow-up of 7 months in these 3 patients, none has shown signs of C1-2 degeneration at this time. The last patient with a superior breach had undergone a $\mathrm{Cl}-3$ fusion, and therefore there was no concern that this breach would lead to subsequent adjacent-segment degeneration in a nonfused segment. The only grade III breach was a superior breach in this last patient. Of the 3 lateral breaches, 2 occurred in patients with high-riding vertebral arteries and axial pedicle diameters of $3.4 \mathrm{~mm}$ and $3.6 \mathrm{~mm}$, respectively, and both were classified as grade I violations. No patients experienced any neurological or vascular complications related to pedicle screw placement. Of note, the majority of breaches occurred superiorly as a result of screw length choice and not as a result of an error in exposure or anatomical trajectory.

Alosh et al. attempted to correlate surgeon experience with breach rate. ${ }^{1}$ They observed an inverse relationship between surgeon experience and $\mathrm{C} 2$ pedicle screw misplacement, showing an overall breach rate of $37 \%$ during placement of the first 10 pedicle screws, which decreased to $22 \%$ for the same surgeons during placement of the 11th to 30th screws. As a comparison in our series of a singlesupervisory surgeon, the overall breach rate was $30 \%$ in the first 10 pedicle screws, a rate that decreased to $13 \%$ for screws 11-40. This underscores the technical challenges of this approach, especially when performed anatomically 


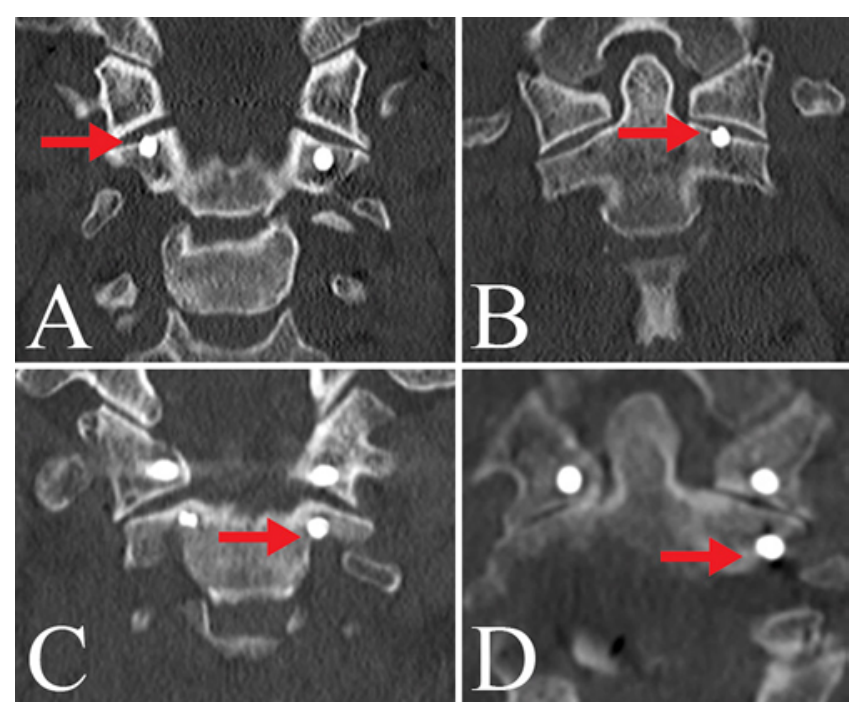

FIG. 3. Coronal CT scans showing a superior grade I breach (A), a superior grade II breach (B), a lateral grade I breach (C), and a lateral grade II breach (D). Arrow in each scan points to the respective breach. Figure is available in color online only.

freehand. Alosh et al. also commented that it was possible that more technically experienced surgeons would be more willing to undertake this approach to explain why surgical volume was inversely associated with breach rate, which highlights the necessity of early trainee exposure for a continued accumulation of this experience through case exposure and instruction. Again, in this series, the 3 youngest trainees at the PGY-2 level placed a total of 17 pedicle screws, a number that will only increase throughout the rest of their neurosurgical training.

Sciubba et al. widely described the anatomical freehand method for placement of $100 \mathrm{C} 2$ pedicle screws using anatomical landmarks in 55 consecutive patients in whom instrumented fusion of $\mathrm{C} 2$ was performed by a single surgeon. ${ }^{6}$ Their technique was based on preoperative imaging and extensive intraoperative exposure of the medial, lateral, and superior aspects of $\mathrm{C} 2$ for visualization of the anatomy. This technique was similarly used in this study with the demonstration that exposure of the anatomy and subsequent freehand placement of the $\mathrm{C} 2$ screw can be accomplished safely even by the novice surgeon as long as there is a strong fundamental understanding of both the expected anatomy at $\mathrm{C} 2$ and the patient's individualized anatomy for that particular operation. A requisite to this would be instruction by a surgeon who was similarly trained to appreciate such, but this underscores again the ability of learning this anatomy and technique early in one's training, when there are opportunities for safe supervision and directed education. In this particular series, surgeon M.H.P. gave all junior neurosurgical residents a lecture on the technique, an opportunity to review a spinal model prior to surgery, and a debriefing of the postoperative CT scan to review placement of the screw and build upon an understanding of their intraoperative technical maneuvers. While the three PGY-2 and two PGY4 residents did have a general interest in spine surgery, due to their early position in residency overall, none had necessarily stated any definitive decision to pursue spine
TABLE 4. Prior studies describing freehand placement of C2 pedicle screws

\begin{tabular}{lccc}
\hline \multicolumn{1}{c}{ Authors \& Year } & $\begin{array}{c}\text { No. of } \\
\text { Patients }\end{array}$ & $\begin{array}{c}\text { No. of C2 } \\
\text { Pedicle Screws }\end{array}$ & $\begin{array}{c}\text { Breach } \\
\text { Rate }\end{array}$ \\
\hline Yeom et al., 2008 & $23^{*}$ & 39 & $21 \%$ \\
\hline Sciubba et al., 2008 & 55 & 100 & $15 \%$ \\
\hline Alosh et al., 2010 & $93 \dagger$ & 170 & $25.3 \%$ \\
\hline Bydon et al., 2014 & 181 & 341 & $17.3 \%$ \\
\hline $\begin{array}{l}\text { * Number of patients also includes patients with C2 laminar screws. } \\
\text { † Fluoroscopy used in 18 cases. }\end{array}$
\end{tabular}

surgery as a postgraduate career. There were no enfolded fellows.

Certainly, the aim of this paper is not to show that any trainee can or should perform a difficult technique confidently alone in the operating room. Rather, it is to highlight that technical surgical education can be learned early (PGY-2 to PGY-4) and that it need not be relegated by convention to the later training years. As with many technical fields, surgical education occurs through a series of repetitive exposures and opportunities, and the residency period is a time for the resident to gather as much experience as possible regardless of training level, especially when it involves anatomy that may be complex or difficult. An argument can be made that this type of early instruction is more valuable, because the early trainees then have more time over the course of their entire residency to learn, understand, and further perfect the technical and anatomical principles behind a maneuver, while still under the safety of residency training oversight. Along that same line, difficult techniques can be taught safely and effectively by a motivated albeit young surgeon late in training who nevertheless possesses a special interest and expertise in a subfield (that is, a PGY-7 surgeon). The accumulation of enough experience to teach a technique is not always fully reflected in how old surgeons are but rather in their accumulated case exposure and in a deep personal interest in that field. Although experience will naturally only accumulate with age and time across years and decades of a distinguished career, the starting point of expertise can be early.

Here we describe the first $40 \mathrm{C} 2$ pedicle screws in a consecutive 24 patients placed by or under the directed supervision of a PGY-7 neurosurgical trainee in his last year of training as a transition to practice, who himself had neurosurgical resident assistants at the PGY-2 to PGY-4 training level. We demonstrate that this maneuver can be taught to and performed safely by neurosurgical resident trainees, even in their early training. A careful understanding of each patient's unique preoperative C2 segment anatomy, along with knowledge of the potential technical pitfalls of the anatomical freehand technique, is of the utmost importance when deciding to use such instrumentation.

\section{Conclusions}

Freehand placement of $\mathrm{C} 2$ pedicle screws can be done safely by neurosurgical residents in early training. When 
breaches occurred, they tended to be superior in location and related to screw length choice, and no breaches were clinically significant. Controlled exposure to this unique anatomy for resident trainees is especially pertinent in the era of work-hour restrictions.

\section{References}

1. Alosh H, Parker SL, McGirt MJ, Gokaslan ZL, Witham TF, Bydon A, et al: Preoperative radiographic factors and surgeon experience are associated with cortical breach of $\mathrm{C} 2$ pedicle screws. J Spinal Disord Tech 23:9-14, 2010

2. Bydon M, Mathios D, Macki M, De la Garza-Ramos R, Aygun N, Sciubba DM, et al: Accuracy of C2 pedicle screw placement using the anatomic freehand technique. Clin Neurol Neurosurg 125:24-27, 2014

3. Goel A, Laheri V: Plate and screw fixation for atlanto-axial subluxation. Acta Neurochir (Wien) 129:47-53, 1994

4. Harms J, Melcher RP: Posterior C1-C2 fusion with polyaxial screw and rod fixation. Spine (Phila Pa 1976) 26:2467-2471, 2001

5. Hu Y, Kepler CK, Albert TJ, Yuan ZS, Ma WH, Gu YJ, et al: Accuracy and complications associated with the freehand C-1 lateral mass screw fixation technique: a radiographic and clinical assessment. J Neurosurg Spine 18:372-377, 2013

6. Sciubba DM, Noggle JC, Vellimana AK, Alosh H, McGirt MJ, Gokaslan ZL, et al: Radiographic and clinical evaluation of free-hand placement of C-2 pedicle screws. Clinical article. J Neurosurg Spine 11:15-22, 2009
7. Sciubba DM, Noggle JC, Vellimana AK, Conway JE, Kretzer RM, Long DM, et al: Laminar screw fixation of the axis. J Neurosurg Spine 8:327-334, 2008

8. Simsek S, Yigitkanli K, Seckin H, Akyol C, Belen D, Bavbek $\mathrm{M}$ : Freehand $\mathrm{C} 1$ lateral mass screw fixation technique: our experience. Surg Neurol 72:676-681, 2009

9. Yeom JS, Buchowski JM, Park KW, Chang BS, Lee CK, Riew KD: Undetected vertebral artery groove and foramen violations during $\mathrm{C} 1$ lateral mass and $\mathrm{C} 2$ pedicle screw placement. Spine (Phila Pa 1976) 33:E942-E949, 2008

\section{Disclosures}

The authors report no conflict of interest concerning the materials or methods used in this study or the findings specified in this paper.

\section{Author Correspondence}

Conception and design: Pham, Bakhsheshian, Liu. Acquisition of data: Pham, Bakhsheshian. Analysis and interpretation of data: Pham, Bakhsheshian, Reid, Buchanan, Fredrickson. Drafting the article: Pham, Bakhsheshian, Reid, Buchanan, Fredrickson. Critically revising the article: all authors. Reviewed submitted version of manuscript: all authors. Study supervision: Pham, Liu.

\section{Correspondence}

Martin H. Pham: LAC+USC Medical Center, Los Angeles, CA. martinpham@gmail.com. 